\title{
Vibration Analysis on Luffa Fiber Reinforced Polyester composites
}

\author{
S. Saravanasankar, G. Kalusuraman, I. Siva
}

\begin{abstract}
The objective of this process is to investigate the free vibration characteristics of luffa fiber reinforced polyester composites. It also includes the experimental investigation on density and hardness of luffa fiber polyester reinforced composites. The simple laminated plate is fabricated using compression molding machines under the pressure 17MPa.The composite specimen were subjected to modal analysis to obtain natural frequencies and damping values. Damping values obtained are increasing according to the increase in weight percentage. The damping values obtained are higher and ever seen in natural fiber
\end{abstract}

Keywords: Luffa fiber, polyester composite, fiber loading, vibration analysis.

\section{INTRODUCTION}

There is a vast usage of natural fibers instead of synthetic fibers as reinforcement in polymer composites for engineering applications. The advantages of natural fiber are low cost, low density with high specific strength and high load carrying capacity. At present the researchers are keen interest on bio-composites which could be considered as potential in the forthcoming generation structural materials. Mainly bio-composites which are mainly used in automotive industrial applications [1]. Libo yan [2] et al investigated treatment effects on the vibration characteristics flax and lien-fabric reinforced epoxy composites and found that after the alkali treatment, the compressive strength and compressive modules increased but damping ratio and impact strength and of the composites were decreased. N Alam et al [3] found that different fiber orientations lead to the maximum frequency and the maximum damping. It is noted that the reduction of amplitude of vibration is most essential in design of machine and its component in industrial applications. The resonance amplitude of vibration is influenced by model damping associates with each mode of model/structure. Berthelot jean-Marie [4] et al reported that damping associated with fiber reinforced composites (FRC) structure is higher than conventional metal structures since it is having fiber matrix behavior and viscoelastic behavior.

Revised Manuscript Received on December 15, 2019.

* Correspondence Author

S.Saravanasankar*, Department of Mechanical Engineering, Kalasalingam Academy of Research and Education, Krishnankoil-626 126, India, Email: ssaravanasankar@yahoo.co.in

G. Kalusuraman, Department of Mechanical Engineering, Kalasalingam Academy of Research and Education, Krishnankoil-626 126, India, Email: Email: kalusunrk@gmail.com

I. Siva , Department of Mechanical Engineering, Kalasalingam Academy of Research and Education, Krishnankoil-626 126, India, Email: isiva@klu.com

Senthil kumar [5] et al investigated and reported that increasing fiber content enhances the mechanical and damping properties of composites. M.K. Rath [6] et al investigated the vibration on hygrothermal environment and found that there was reduction in natural frequency with the increase in temperature. In this context, vibration test on luffa fiber reinforced polyester composites is carried out for different fiber loading. It also includes investigation on density and hardness of luffa fiber reinforced polyester composites for different weight percentage

\section{EXPERIMENTAL PROCEDURE}

\section{A. Materials and methods}

Luffa fibers used in this study were provided by meenakshi exports, Madurai, Tamilnadu, India. Unsaturated Isophthalic polyester resin (USP), accelerator and initiator were supplied by Vasavibala resins (P) Ltd., Chennai, India.

\section{B. Composite fabrication and testing}

The luffa fiber is taken from luffa fruit. It is cylindrical in shape. The fiber must go through cutting to change it from cylindrical form to flat form and also to remove unwanted things from the fiber. After that it was placed in the mold of $300 \times 125 \times 3 \mathrm{~mm} 3$ and compressed in compression molding machine for pre compression. Now the mold surface is applied with mansion wax as releasing agent. Then the mixture of $200 \mathrm{ml}$ resin, $3 \mathrm{ml}$ accelerator and catalyst is taken in a beaker. The luffa fiber is placed layer by layer. The mold is closed and placed in compression molding machine for curing with minimum pressure of $170 \mathrm{~kg} / \mathrm{sq} \mathrm{cm}$ for 4 hours.

\section{Rheological testing}

Density of the composites was measured as per the ASTM: D256 using SHIMADZU weighing balance with a density pit which works on Archimedes principle with the accuracy of $0.1 \mathrm{mg}$. The density was calculated from the formula given below,

Density, $\rho=a /(a+b-w)$

Where,

Where, $\rho=$ Density in $\mathrm{kg} / \mathrm{m} 3, \mathrm{a}=$ weight of the specimen in air, $b=$ weight of the specimen in water + weight of the hanger, $\mathrm{w}=$ weight of the hanger 
In order to find the hardness, Shore D hardness test was performed using a durometer as per ASTM: D256. Initially cleaned and dried samples were pinged with the indenter of the Shore D hardness tester. Based on the depth produced direct measure of hardness values were obtained from dial indicator.

\section{MODAL ANALYSIS}

Modal analysis is the study of the natural characteristics of structures. The natural frequency damping and made shape are used to help in designing the system for vibration applications. Model analys is helped in design on structure of aircraft structures, spacecraft and automotive structures, there are many types of methods for performing modal analysis, in which vibration shaker test and impact hammer test are most probably used. Impact hammer test is carried out with a impact modal hammer and a response accelerometer associated with DEWE software. In this study modal analysis is done with Kistler $8778 \mathrm{~A}$ sensor and specimen $(120 \times 20 \times 3$ $\mathrm{mm})$. The impact hammer imparts an impulse force into the specimen and the output of the impact hammer and accelerometer are utilized to find the frequency response functions throughout the specimen. The output is recorded in a PC using data acquisition system (DAS) and ICP conditioner. [5-6]

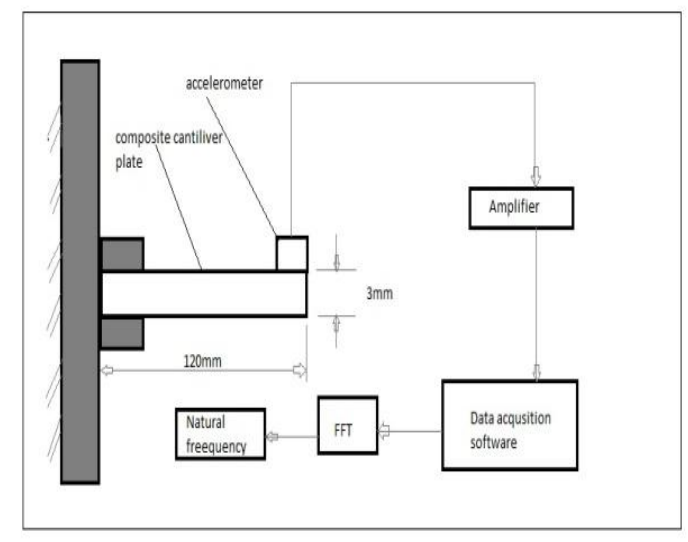

Fig:1 schematic representation of modal analysis

\section{A. Damping factor}

Damping is the energy dissipation properties of a material under cyclic stress. Dynamic characteristics of composite specimen are studied using damping factor. An auxiliary equation is used to obtain the damping values of luffa fiber reinforced polyester composites through frequency response function (FRF) curves obtained from the fast fourier transform (FFT) analyzer. Damping values are found by the following equation [7-9]

$$
\mathrm{X}_{\mathrm{n}} / \mathrm{X}_{\mathrm{n}+1=} \mathrm{e}^{\varepsilon * \cos m \mathrm{Td}}
$$

Where,

Xn-amplitude of 1 st peak

$\mathrm{Xn}+1$ - amplitude of 2 nd peak

$\varepsilon$ - Damping factor

$\mathrm{n}$-Natural frequency

Td - Time interval

\section{RESULT AND DISCUSSION}

\section{A. Density and hardness}

The following figure 1 shows the density values of untreated luffa fiber reinforced polyester composite. The density value increased for $40 \mathrm{wt} . \%$ of the composite. The density value for $30 \mathrm{wt} . \%$ is decreased due to poor interfacial adhesion. Density can be improved by enhancing the interfacial adhesion.

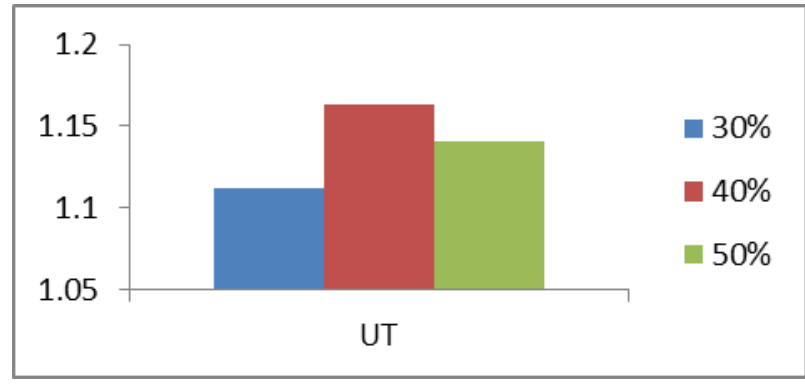

Fig: 2 Effect of fiber loading on density

The shore $\mathrm{D}$ hardness of the composite is given in the following figure 2 . The hardness values are increasing according to the weight percentage of untreated luffa fiber reinforced polyester composite.

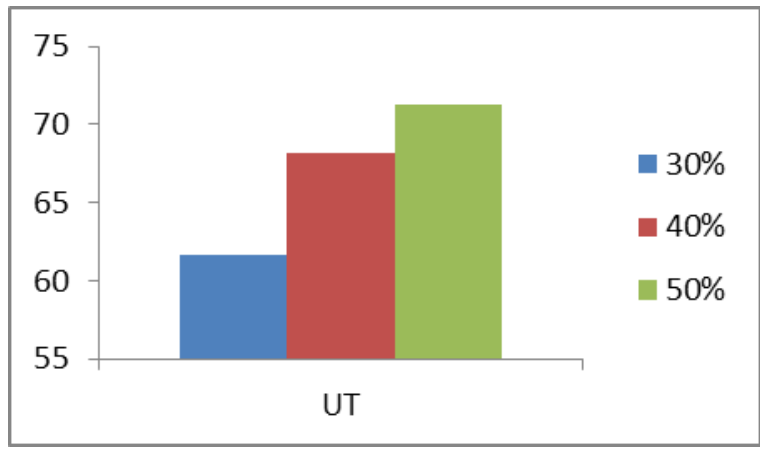

Fig: 3 Effect of fiber loading on hardness

\section{B. Natural frequency}

Natural frequency of the untreated luffa fiber reinforced polyester composite is shown in the following figure 3. Natural frequency of the composite is increasing according to the weight percentage.50 wt $\%$ combination shows higher natural frequency values $(0.361312$ for mode 1$)$ because of their high fiber/matrix combination. Whereas,30 wt\% shows low frequency values $(0.273798$ for mode 1$)$ because of their poor interfacial adhesion and low fiber/matrix combination.

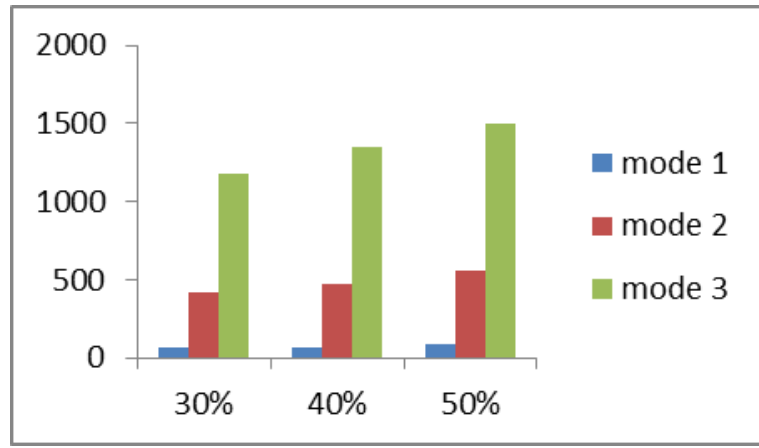

Fig :4 Comparison of natural frequency 


\section{Damping factor}

Damping values obtained is higher and ever seen in natural fibers. It is understanding that some of gap adjacent fiber and matrices might be there in the Untreated composite. Theses noted gap might be responsible for energy dissipation by fiber/matrix during vibrating condition. For untreated composite, there are noticeable gaps between the adjacent fibers and matrices; this indicates a poor fiber/matrix interfacial adhesion. These noticeable gaps are responsible for dissipating energy by fiber/matrix friction during the vibrations. The following figure 4 shows the damping factor of untreated luffa fiber reinforced polyester composite.

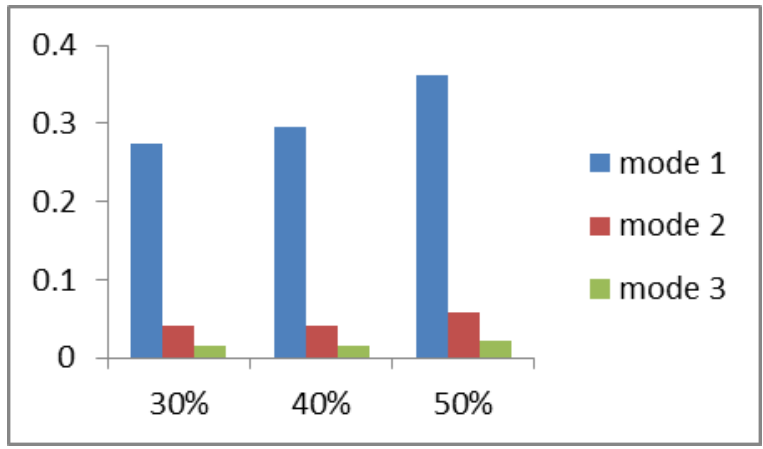

Fig: 5 Comparison of damping ratio

\section{CONCLUSIONS}

The following conclusions were made.

$>$ Untreated luffa fiber reinforced polyester composite was produced by using compression molding technique for different combination of weight percentage.

$>$ Density of the composite is increased for $40 \% \mathrm{wt}$ combination of fiber/matrix due to good interfacial adhesion.

$>$ The hardness values are increasing according to the weight percentage of untreated luffa fiber reinforced polyester composite.

$>$ Natural frequencies are increased for $50 \%$ wt. combination of fiber/ matrix.

$>$ Damping values obtained is increased due to poor interfacial adhesion between fiber/matrix in untreated composite. Also

\section{REFERENCES}

1. Bordes, Perrine, Eric Pollet, and Luc Avérous. "Nano-biocomposites: biodegradable polyester/nanoclay systems." Progress in Polymer Science 34, no. 2 (2009): 125-155.

2. Yan, Libo. "Effect of alkali treatment on vibration characteristics and mechanical properties of natural fabric reinforced composites." Journal of Reinforced Plastics and Composites 31, no. 13 (2012): 887-896.

3. Alam, N., and N. T. Asnani. "Vibration and damping analysis of fibre reinforced composite material plates." Journal of composite materials 20, no. 1 (1986): 2-18.

4. Berthelot, Jean-Marie. "Damping analysis of orthotropic composites with interleaved viscoelastic layers: modeling." Journal of composite materials 40, no. 21 (2006): 1889-1909.

5. K. Senthil kumar, I. Siva, P. Jeyaraj, J.T.winowlin jappes, S.C Amico, N. Rajini. Synergy of fiber length and content on free vibration and damping behavior of natural fiber reinfoced polyester composite beam. 56 (2014) 379-386.
6. Rath, M. K., and S. K. Sahu. "Vibration of woven fiber laminated composite plates in hygrothermal environment." Journal of vibration and control 18, no. 13 (2012): 1957-1970.

7. Sakthivel, M., and S. Ramesh. "Mechanical properties of natural fibre (banana, coir, sisal) polymer composites." Science park 1, no. 1 (2013): 1-6.

8. Karaagac, Celalettin, Hasan Ozturk, and Mustafa Sabuncu. "Effects of an edge crack on the free vibration and lateral buckling of a cantilever laminated composite slender beam." Journal of Vibration and Control 19 , no. 16 (2013): 2506-2522.

9. Cevik, Mehmet. "Effects of Fiber Orientation on Out-of-plane and In-plane Natural Frequencies of Angle-ply Laminated Composite Arches." Journal of Reinforced Plastics and Composites 28, no. 1 (2009): 59-71.

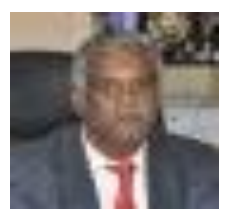

\section{AUTHORS PROFILE}

Dr.S. Saravanasankar is currently working as Professor in the Department of Mechanica Engineering, Kalasalingam Academy of Research and Education, Anand nagar, Krishnankoil-626126, India He has 20 years teaching as well as research experience He is a Member of Indian Society for Technical Education. He has published more than 50 international journals. He is working in the field of scheduling, optimization and composite materials.

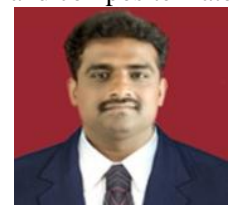

Dr. G. Kalusuraman is currently working as Associate Professor in the Department of Mechanical Engineering, Kalasalingam Academy of Research and Education, Anand nagar, Krishnankoil-62612., India He has 10 years teaching as well as research experience. He is a reviewer for two reputed journals He is a Member of Indian Society for Technical Education. His areas of interest are polymer composite, materials characterization and tribology.

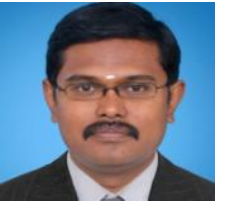

Dr. I. Siva is currently working as Professor in the Department of Mechanical Engineering, Kalasalingam Academy of Research and Education, Anand nagar, Krishnankoil-626126, India He has 15 years teaching as well as research experience. He is a reviewer more than 50 reputed journals $\mathrm{He}$ is a Member of Indian Society for Technical Education. His areas of interest are polymer composite, materials characterization, tribology, FML 